\title{
Heterogeneity of glomerular perfusion and filtration induced by epinephrine and norepinephrine
}

M.A. Boim, S.R. Stella, A.B. Pereira and N. Schor
Disciplina de Nefrologia, Universidade Federal de São Paulo, 04023-900 São Paulo, SP, Brasil

\section{Correspondence}

N. Schor

Departamento de Medicina UNIFESP

Escola Paulista de Medicina

Rua Botucatu, 740

04023-062 São Paulo, SP

Brasil

Fax: 55 (011) 573-9652

E-mail: nschor.dmed@epm.br

Research supported by FAPESP CNPq, FINEP and Fundação

Oswaldo Ramos.

$\ldots \ldots \ldots \ldots \ldots \ldots \ldots \ldots$

Received November 22, 1996 Accepted June 23, 1997

\begin{abstract}
The role of catecholamines in the distribution of intrarenal blood flow and in single-nephron glomerular filtration rate (SNGFR) was evaluated in anesthetized Wistar rats by the Hanssen technique. Epinephrine (EPI) and norepinephrine (NOR) were infused to produce elevations of $20-30 \mathrm{mmHg}$ in mean arterial pressure. Superficial and juxtamedullary nephron perfusion and filtration were determined by the presence of Prussian blue dye. In the control group, $100 \%$ of the nephrons presented a homogeneous pattern of perfusion and filtration. In contrast, a heterogeneous distribution of the dye was found even in the larger arteries (arciform and radial), indicating variable perfusion and filtration in both superficial and juxtamedullary nephrons. The effects of EPI and NOR were also evaluated in the superficial cortex by the micropuncture technique in two additional groups of MunichWistar rats. Mean SNGFR was 27\% and 54\% lower in the EPI- and NOR-treated groups, respectively. No change in mean intraglomerular hydraulic pressure was observed after EPI or NOR infusion in spite of a highly scattered pattern, indicating an important variability in perfusion along the superficial cortex, and/or different sensitivity of the preand post-glomerular arterioles. The present data suggest that EPI and NOR may affect intrarenal hemodynamics by modifying perfusion and filtration in both superficial and juxtamedullary glomeruli and not by shifting blood flow from superficial to juxtamedullary nephrons. The heterogeneous pattern of perfusion was a consequence of differential vasoconstriction along the intrarenal arteries, probably due to different density and/or sensitivity of the adrenergic receptor subtypes present in the intrarenal vascular tree.
\end{abstract}

\section{Introduction}

The distribution of intrarenal blood flow among the different nephron populations may play an important physiological and pathophysiological role. These differences are mediated in part by sympathetic neural control since the renal vasculature and other parts of the nephron receive extensive noradrenergic innervation (1). Moreover, the
Key words

- Catecholamines

- Intrarenal blood flow

- Glomerular function

- Hanssen technique

- Micropuncture kidney presents a high concentration of adrenergic receptors (1-4) and, based on pharmacological and molecular techniques, the expression of the $\alpha$ - and $\beta$-adrenergic receptor subtypes has been observed in the different regions of the nephron (5-8).

Renal nerves participate in renal vasoconstriction in several situations such as dehydration, blood volume contraction, hemorrhage, congestive heart failure and arterial 
hypoxemia (9). Also, changes in renal blood flow have been observed when renal nerves are stimulated or catecholamines are infused (10), causing a reduction in outer cortical blood flow and redistribution to the inner cortex and outer medulla (11). However, studies evaluating intrarenal blood flow distribution under different conditions and by different techniques have produced conflicting results (11-16). Therefore, we have reinvestigated the question of the distribution of blood flow in superficial and juxtamedullary nephron populations during renal vasoconstriction induced by epinephrine (EPI) and norepinephrine (NOR) using the Hanssen technique. In addition, the functional behavior of the superficial nephrons was investigated by micropuncture.

\section{Material and Methods}

\section{Renal blood flow distribution - Hanssen technique}

Adult male Wistar rats were divided into three groups: control $(\mathrm{N}=10), \mathrm{EPI}(\mathrm{N}=9)$ and NOR $(\mathrm{N}=13)$. Rats were randomly assigned to the groups and had free access to tap water, but not to food the night before the experiment. Animals were anesthetized with sodium pentobarbital (Nembutal, $50 \mathrm{mg} / \mathrm{kg}$ body weight) and submitted to the surgical procedures. After tracheotomy, both jugular veins were catheterized (PE-50) for continuous infusion of inulin (300 $\mathrm{mg} \%)$ and $\mathrm{p}$ aminohippuric acid (PAH) $(40 \mathrm{mg} \%)$ at a rate of $0.051 \mathrm{ml} / \mathrm{min}$. The left carotid artery was catheterized for periodic blood sampling and to monitor mean arterial pressure (MAP) with a mercury manometer. A polyethylene catheter (PE-60) was introduced into the bladder for urine collection. Finally, loose ligatures were placed around the renal pedicles.

After a 30-min equilibration period, urine and blood were collected during two control periods of 30 min each for the determination of inulin and PAH clearance. After the control collections, EPI or NOR was infused into the left jugular vein in order to produce increases of 20-30 $\mathrm{mmHg}$ in mean arterial pressure, which were obtained with doses of 2.5$5.0 \mu \mathrm{g} \mathrm{kg}^{-1} \mathrm{~min}^{-1}$ of EPI and 1.3-2.5 $\mu \mathrm{g} \mathrm{kg}^{-1}$ $\mathrm{min}^{-1}$ of NOR. The control group was infused with saline $(0.3 \mathrm{ml})$. After MAP stabilization, inulin and PAH clearances were again determined.

At the end of the second experimental period, a solution of $10 \%$ Lissamine green was infused and the green color was observed in a previously exposed intestinal loop. A solution of $10 \%$ sodium ferrocyanide (250 $\mathrm{mg} / \mathrm{kg}$ body weight) was then infused intravenously in bolus. Ten seconds later both renal pedicles were tied and the kidneys were immediately removed and dropped into a solution of acetone and dry ice at $-70^{\circ} \mathrm{C}$. Frozen kidneys were fragmented and immersed in a saturated ferric chloride solution at $-20^{\circ} \mathrm{C}$ for $16-20 \mathrm{~h}$. The reaction between ferric chloride and sodium ferrocyanide produces a stable Prussian blue precipitate. The pieces were then incubated with hydrochloric acid (7.4\% $\mathrm{v} / \mathrm{v})$ for $6 \mathrm{~h}$ at $37^{\circ} \mathrm{C}$. Kidney slices were then rinsed with distilled water and kept at $4^{\circ} \mathrm{C}$ (17). About 20 superficial and 20 juxtamedullary nephrons containing a full proximal tubule were dissected from each kidney under a stereomicroscope. The nephrons were assembled on a slide and the full length of the proximal tubule as well as the part stained with the dye was measured with a curvimeter. Randomized right kidneys from all groups were submitted to histological evaluation.

\section{Micropuncture studies}

Superficial single-nephron glomerular filtration rate (SNGFR) and hydraulic pressures of glomeruli $\left(\mathrm{P}_{\mathrm{GC}}\right)$, tubules $\left(\mathrm{P}_{\mathrm{T}}\right)$, efferent arterioles $\left(\mathrm{P}_{\mathrm{EA}}\right)$ and peritubular capillaries $\left(\mathrm{P}_{\mathrm{C}}\right)$ 
were determined in 22 additional adult male Munich-Wistar rats under hydropenic conditions. Animals were prepared for micropuncture as previously described $(18,19)$. Briefly, rats were anesthetized with inactin (BYK, Konstanz, Germany) (100 mg/kg body weight) and placed on a temperature regulated table. After tracheotomy, the left femoral artery was catheterized (PE-50) for blood sampling and MAP recording (Recorder model 2.200, Gould Inc., Cleveland, OH). A polyethylene catheter (PE-50) was inserted into the left jugular vein for infusion of inulin $(7.5 \%, 1.2 \mathrm{ml} / \mathrm{h})$. Laparotomy was then performed and the left kidney was prepared for micropuncture.

After a 45-min equilibration period, fluid samples were collected from surface proximal tubules for the determination of flow rate and inulin concentration (20) and calculation of SNGFR. Simultaneously, samples of femoral arterial blood were obtained for the determination of hematocrit, total protein and inulin concentration in plasma (21), and systemic arterial pressure was recorded.

Direct measurements of $\mathrm{P}_{\mathrm{GC}}, \mathrm{P}_{\mathrm{T}}, \mathrm{P}_{\mathrm{EA}}$ and $\mathrm{P}_{\mathrm{C}}$ were made with a continuous recording Servonull micropipette-transducer system (IPM Inc., San Diego, CA). After urine and blood collections during a control period, EPI or NOR was infused as described earlier and SNGFR and pressure were again measured.

Data obtained with the micropuncture technique (hydraulic pressures and superficial SNGFR) before and after drug administration were analyzed statistically by the Student $t$-test.

\section{Results}

Animals had similar body weights with mean values of $230 \pm 30 \mathrm{~g}$ for control, $207 \pm$ $33 \mathrm{~g}$ for EPI- and $211 \pm 38 \mathrm{~g}$ for NOR-infused animals. Catecholamine infusion induced non-significant elevations $(\sim 10 \%)$ in hemat- ocrit (46 $\pm 5 \%$ for the NOR group and $47 \pm$ $4 \%$ for the EPI group) compared with control $(43 \pm 3 \%)$.

Figure 1 shows the qualitative distribution of Prussian blue. Kidneys were classified according to the pattern of macroperfusion indicated by the presence of Prussian blue as A) homogeneously ischemic, B) heterogeneously perfused and C) homogeneously perfused.

Figure 2 shows a heterogeneously perfused kidney slice from a NOR-treated rat. The figure shows glomeruli with variable amounts of Prussian blue (A), with normal or heterogeneous perfusion, and areas with ischemic glomeruli (B).

Figure 3 presents an arciform artery from a NOR-treated rat with a well-perfused segment (A), a segmental vasoconstriction (B) with crystals of Prussian blue and a distal ischemic segment (C).

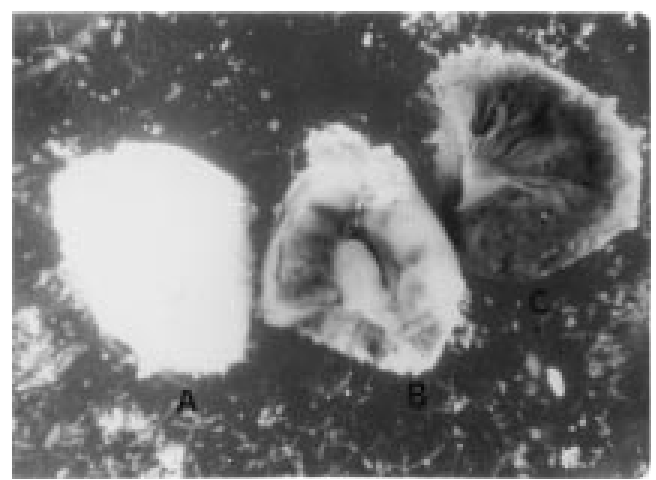

Figure 1 - Qualitative distribution of Prussian blue in homogeneously ischemic $(A)$, heterogeneously perfused (B) and homogeneously perfused (C) kidneys.

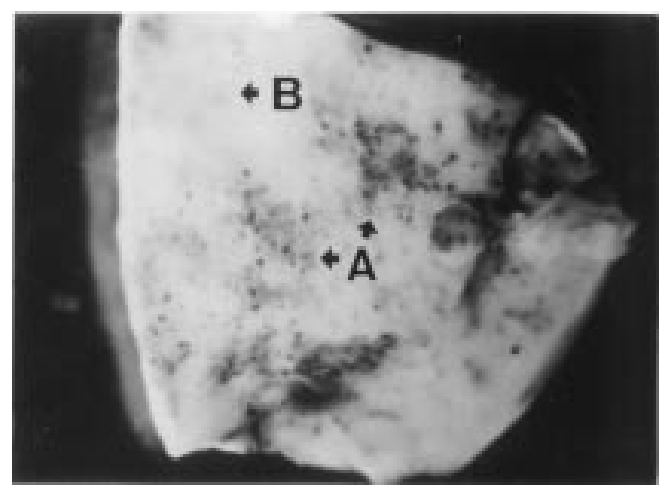

Figure 2 - Heterogeneously perfused kidney slice from a norepinephrine-treated rat. $A$, Area with perfused glomeruli; $B$, area with ischemic glomeruli. 
Figure 3 - Arciform artery from a norepinephrine-treated rat with a heterogeneously perfused kidney. A, Well-perfused segment (presence of Prussian blue); $B$, segmental vasoconstriction; $C$, ischemic segment (distal portion of the artery).

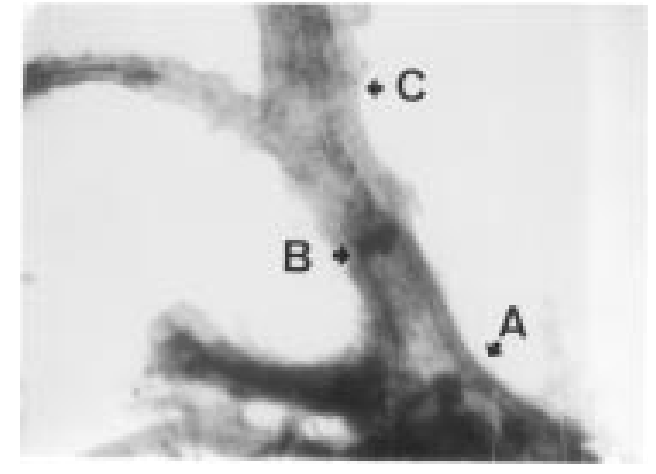

Based on these patterns of perfusion, animals were subdivided as follows: control group $(\mathrm{N}=10)$ : homogeneously perfused ( $\mathrm{N}$ $=10)$; NOR- treated group $(\mathrm{N}=13)$ : homogeneously perfused (NOR-HP, $\mathrm{N}=4$ ), heterogeneously perfused (NOR-HTP, $\mathrm{N}=4$ ), homogeneously ischemic (NOR-HI, $\mathrm{N}=5$ ); EPI-treated group $(\mathrm{N}=9)$ : homogeneously perfused (EPI-HP, $\mathrm{N}=5$ ), heterogeneously perfused (EPI-HTP, $\mathrm{N}=4$ ).

As shown in Table 1, animals treated with EPI or NOR presented an increase of about $20-30 \mathrm{mmHg}$ in mean arterial pressure, regardless of whether the pattern of perfusion was homogeneous or heterogeneous. Total glomerular filtration rate (GFR) and renal plasma flow (RPF) were significantly reduced $(\mathrm{P}<0.05)$ only in the NOR-HI subgroup.

Table 2 shows the qualitative distribution of Prussian blue in the glomeruli, which was scored as absent or present at levels from 1+ to 4+. One hundred percent of the superficial and juxtamedullary glomeruli from control animals showed regular distribution of Prussian blue, indicating normal glomerular perfusion. In glomeruli from animals treated with EPI or NOR the distribution of the dye was irregular in both homogeneously and heterogenously perfused kidneys. However, in homogeneously ischemic NOR-treated animals, the dye was absent in $100 \%$ of the glomeruli.

A representative index of SNGFR esti- mated by the Hanssen technique $\left(\mathrm{SNGFR}_{\mathrm{H}}\right)$ in superficial and juxtamedullary nephrons is shown in Table 3. This index was obtained as percent length of proximal tubule filled with Prussian blue. The table also shows the percentage of non-filtering nephrons determined by the presence or absence of the dye in the proximal tubules. The filtering nephrons from the EPI- and NOR-treated groups presented a lower and variable $\mathrm{SNGFR}_{\mathrm{H}}$ index compared to control animals. Moreover, in the homogeneously ischemic NOR group, Prussian blue was absent in $100 \%$ of the glomeruli examined, indicating that the nephrons became non-filtering.

Figure 4 shows the SNGFR and hydraulic pressures obtained by the micropuncture technique before and after EPI or NOR administration. Values represent individual measurements for each rat. Mean tubular hydraulic pressure was not changed by epinephrine or norepinephrine infusion. The hydraulic pressure in efferent arterioles presented high scattering in both the EPI and NOR groups, but the mean value was significantly $(\mathrm{P}<0.05)$ elevated in the EPI group compared to the control period $(13.3 \pm 0.7 v s$ $17.5 \pm 1.1 \mathrm{mmHg}$ ). No change in mean glomerular hydraulic pressure was observed after EPI or NOR infusion, but highly scattered data were observed in the NOR group. SNGFR obtained from superficial nephrons also showed variable values after EPI or NOR infusion. However, mean SNGFR was significantly reduced in both groups (EPI: $25.9 \pm 2.2$ vs $19.0 \pm 2.3 \mathrm{nl} / \mathrm{min}(\mathrm{P}<0.05)$ and NOR: $25.0 \pm 1.1$ vs $11.7 \pm 1.7 \mathrm{nl} / \mathrm{min}$ $(\mathrm{P}<0.05))$ when compared to the control period.

\section{Discussion}

The distribution of intrarenal blood flow plays an important role in the control of glomerular filtration rate, urine concentra- 
tion and sodium excretion (22). It has been suggested that under certain conditions such as hemorrhage and dehydration the normal distribution of blood flow may shift from superficial to juxtamedullary nephrons, so that sodium and volume losses are minimized (23).

The renal nerves are known to influence several kidney functions $(3,24)$, including blood flow distribution $(11,12)$. During intensive sympathetic stimulation, such as cold exposure or exhausting exercise, catecholamines may alter renal blood flow and total glomerular filtration rate $(11,12)$. Moreover catecholamines play an important role in the pathogenesis of essential hypertension in men (25) due to overactivity of the sympathetic nervous system (25), overproduction of epinephrine and norepinephrine (26) and disorders related to adrenergic receptors due to a higher density $(27,28)$ and/or responsiveness (29). As commented above, the increase in catecholamines induces several renal effects, among them a decrease in renal sodium excretion with a consequent change in the normal relationship between blood pressure and natriuresis, so that higher blood pressure levels are required to initiate pressure diuresis (30). Several mechanisms have been demonstrated to be responsible for sodium retention mediated by catecholamines. However, it is still unclear whether catecholamine-induced changes in the distribution of intrarenal blood flow is one of the possible mechanisms.

Although the influence of catecholamines on renal blood flow distribution has been investigated using several methodologies, the results are conflicting since most of the available techniques present limitations in measuring the distribution of renal blood flow to the deeper portions of the nephron. The present study evaluated the participation of norepinephrine and epinephrine in the distribution of intrarenal blood flow and
Table 1 - Mean arterial pressure (MAP), total glomerular filtration rate (GFR) and renal plasma flow (RPF) in the control group and in the subgroups of rats treated with norepinephrine (NOR) and epinephrine (EPI), showing a homogeneously (HP) and heterogeneously (HTP) perfused and homogeneously ischemic (HI) pattern.

Data are reported as means $\pm \mathrm{SD}$. ${ }^{*} \mathrm{P}<0.05$ vs control ("Destaque e Priori" test).

\begin{tabular}{lccc}
\hline Group & $\begin{array}{c}\text { MAP } \\
(\mathrm{mmHg})\end{array}$ & $\begin{array}{c}\text { GFR } \\
\left(\mathrm{ml} \mathrm{kg}^{-1} \mathrm{~min}^{-1}\right)\end{array}$ & $\begin{array}{c}\text { RPF } \\
\left(\mathrm{ml} \mathrm{kg}^{-1} \mathrm{~min}^{-1}\right)\end{array}$ \\
\hline Control $(\mathrm{N}=10)$ & $133 \pm 8$ & $4.43 \pm 0.97$ & $15.80 \pm 3.00$ \\
NOR-HP $(\mathrm{N}=4)$ & $162 \pm 3^{*}$ & $4.90 \pm 2.31$ & $11.35 \pm 5.13$ \\
NOR-HTP $(\mathrm{N}=4)$ & $172 \pm 4^{*}$ & $3.23 \pm 0.66$ & $14.85 \pm 7.36$ \\
NOR-HI $(\mathrm{N}=5)$ & $163 \pm 8^{*}$ & $0.73 \pm 0.94^{*}$ & $3.70 \pm 4.13^{*}$ \\
EPI-HP $(\mathrm{N}=5)$ & $153 \pm 4^{*}$ & $5.50 \pm 2.67$ & $16.25 \pm 3.39$ \\
EPI-HTP $(\mathrm{N}=4)$ & $157 \pm 6^{*}$ & $6.73 \pm 0.75$ & $20.43 \pm 5.37$
\end{tabular}

Table 2 - Number of Prussian blue granules in the glomeruli of superficial nephrons (SN) and juxtamedullary nephrons (JN) in the control group and in the subgroups of rats treated with norepinephrine (NOR) and epinephrine (EPI), showing a homogeneously (HP) and heterogeneously (HTP) perfused and homogeneously ischemic (HI) pattern.

\begin{tabular}{|c|c|c|c|c|c|}
\hline \multirow[t]{2}{*}{ Group } & \multicolumn{5}{|c|}{ Prussian blue granules } \\
\hline & Absent (\%) & $+(\%)$ & $++(\%)$ & $+++(\%)$ & $++++(\%)$ \\
\hline \multicolumn{6}{|c|}{ Control $(N=10)$} \\
\hline SN & 0 & 0 & 0 & 0 & 100 \\
\hline $\mathrm{JN}$ & 0 & 0 & 0 & 0 & 100 \\
\hline \multicolumn{6}{|c|}{ NOR-HP (N = 4) } \\
\hline SN & 27 & 27 & 12 & 23 & 11 \\
\hline $\mathrm{JN}$ & 40 & 20 & 2 & 13 & 25 \\
\hline \multicolumn{6}{|c|}{ NOR-HTP $(\mathrm{N}=4)$} \\
\hline SN & 23 & 16 & 10 & 19 & 32 \\
\hline $\mathrm{JN}$ & 65 & 8 & 10 & 3 & 14 \\
\hline \multicolumn{6}{|c|}{ NOR-HI (N = 5) } \\
\hline SN & 100 & 0 & 0 & 0 & 0 \\
\hline$J N$ & 100 & 0 & 0 & 0 & 0 \\
\hline \multicolumn{6}{|c|}{ EPI-HP (N = 5) } \\
\hline SN & 15 & 15 & 19 & 24 & 27 \\
\hline $\mathrm{JN}$ & 34 & 10 & 9 & 18 & 29 \\
\hline \multicolumn{6}{|c|}{ EPI-HTP (N = 4) } \\
\hline SN & 39 & 6 & 6 & 0 & 49 \\
\hline $\mathrm{JN}$ & 47 & 6 & 0 & 0 & 49 \\
\hline
\end{tabular}


glomerular filtration rate during elevations of $20-30 \mathrm{mmHg}$ in mean arterial pressure. We used two different techniques to evaluate first the distribution of intrarenal blood flow and glomerular filtration rates in cortical and juxtamedullary nephrons by the Hanssen technique, and then the superficial cortex single nephron function by the micropuncture technique.

The doses of epinephrine and norepinephrine employed in the present study induced an elevation of about $20-30 \mathrm{mmHg}$ in systemic arterial pressure. Whole kidney glomerular filtration rate and renal plasma flow presented a variability among animals from all groups treated with EPI or NOR (as shown by a high standard deviation, Table 1). However, these results agree with those obtained by the Hanssen technique in the present study, where a heterogeneous distribution of the dye was observed, i.e., a heterogeneous response to these drugs. Also, different patterns of perfusion were obtained in these experiments with homogeneously perfused, heterogeneously perfused and homoge-

Table 3 - Representative single nephron glomerular filtration rate in superficial (SN) and juxtamedullary (JN) nephrons obtained by the Hanssen technique.

Percent length of proximal tubules (PT) filled with Prussian blue (PB), and percent of non-filtering nephrons (NFN) in the control group and in the subgroups of rats treated with norepinephrine (NOR) and epinephrine (EPI), showing a homogeneously (HP) and heterogeneously (HTP) perfused and homogeneously ischemic (HI) pattern. Data are reported as means $\pm S D$

\begin{tabular}{|c|c|c|c|c|}
\hline \multirow[b]{2}{*}{ Group } & \multicolumn{2}{|c|}{ PB/PT (\%) } & \multicolumn{2}{|c|}{ NFN (\%) } \\
\hline & SN & $\mathrm{JN}$ & SN & $\mathrm{JN}$ \\
\hline Control & $69 \pm 13$ & $72 \pm 12$ & 0 & 0 \\
\hline NOR-HP & $15 \pm 23$ & $26 \pm 41$ & 60 & 50 \\
\hline NOR-HTP & $9 \pm 18$ & $4 \pm 19$ & 70 & 90 \\
\hline NOR-HI & 0 & 0 & 100 & 100 \\
\hline EPI-HP & $20 \pm 21$ & $20 \pm 27$ & 50 & 50 \\
\hline EPI-HTP & $30 \pm 44$ & $32 \pm 43$ & 50 & 50 \\
\hline
\end{tabular}

neously ischemic kidneys. During microdissection an irregular quantity of precipitate was observed, mainly in the arcuate and radial (interlobular) arteries, ranging from high density to total absence of the dye in the same artery, as shown in Figure 2. This finding may be related to the quantity and/or affinity of the receptors, which may vary along the artery. Epinephrine and norepinephrine induce vasoconstriction of the renal vascular beds by an alpha-adrenergic receptor-mediated mechanism (31). By using pharmacological techniques and more recently molecular approaches, $\alpha$ - and $\beta$ adrenergic receptor subtypes have been identified and specifically localized in the kidney $(8,32,33)$. The rat kidney expresses $\alpha-1 \mathrm{~A}, \alpha-$ $1 \mathrm{~B}, \alpha-2 \mathrm{~A}, \alpha-2 \mathrm{~B}, \beta 1$ and $\mathrm{B} 2$ adrenergic receptor subtypes, which are heterogeneously distributed in the vessels, tubules and ureter $(5,8,33)$. Moreover, the selectivity and sensitivity of these receptors differ with variable responses to different agonists which may also be tissue specific (34). Thus, a more intensive action of these drugs may be expected in specific areas, with severe constriction and total obstruction of the lumen, inducing ischemia in the region which should be perfused by this artery. Thus, the highly irregular distribution of blood flow in both the cortical and juxtamedullary portions of the kidney could be explained by the irregular distribution and/or sensitivity of the receptor along the vascular tree.

Epinephrine and norepinephrine infusion induced important modifications in intrarenal perfusion. However, with the exception of the NOR-HI, the other groups presented no alterations in the total glomerular filtration rate or renal plasma flow, although these groups presented substantial modifications in the glomerular filtration of the superficial and juxtamedullary nephrons when analyzed by the Hanssen technique. It is worthwhile to consider that the Hanssen technique indi- 
cates the percentage of proximal tubules filled with Prussian blue precipitate. The fact that the proximal tubules of the juxtamedullary nephrons are larger suggests a larger volume of glomerular filtrate in this nephron population. For this reason, the function of the superficial nephrons was further evaluated by direct measurement of the glomerular filtration of superficial nephrons by the micropuncture technique in different areas of the renal surface. The results showed wide variability of the SNGFR due to the variability of perfusion.

The evaluation of superficial SNGFR by the micropuncture technique showed a high variability among punctured nephrons, even

\section{Epinephrine}

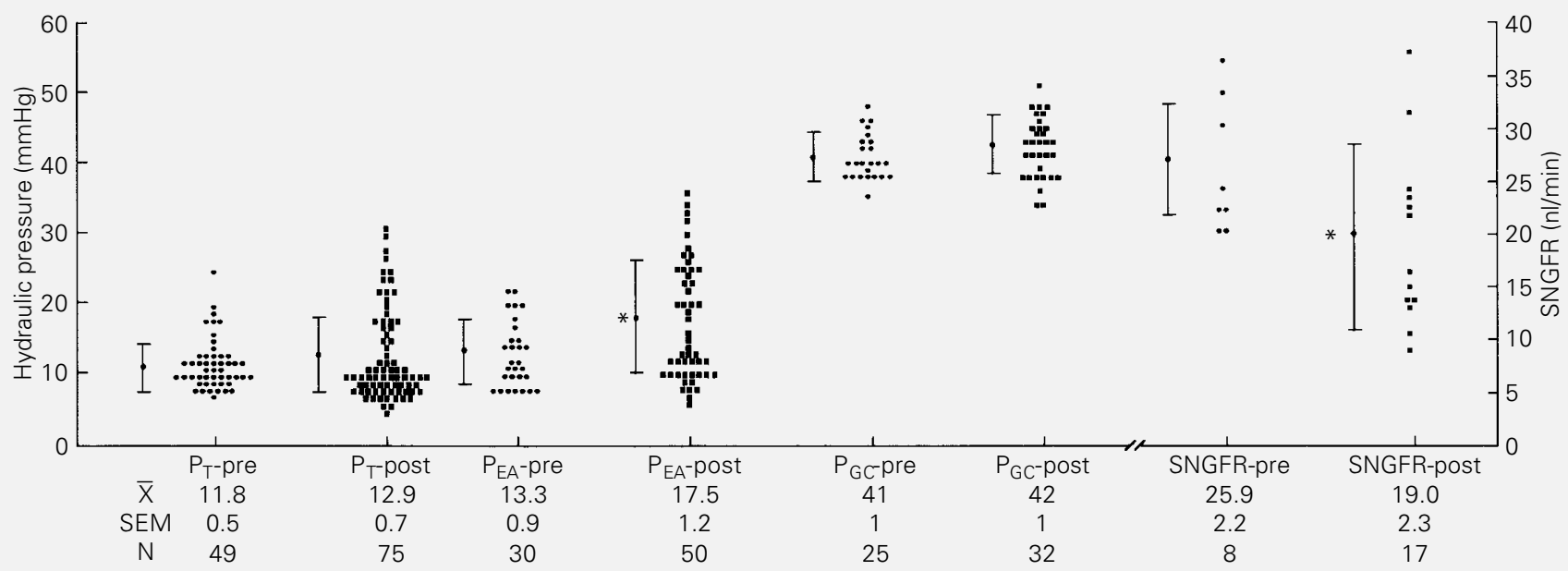

Norepinephrine

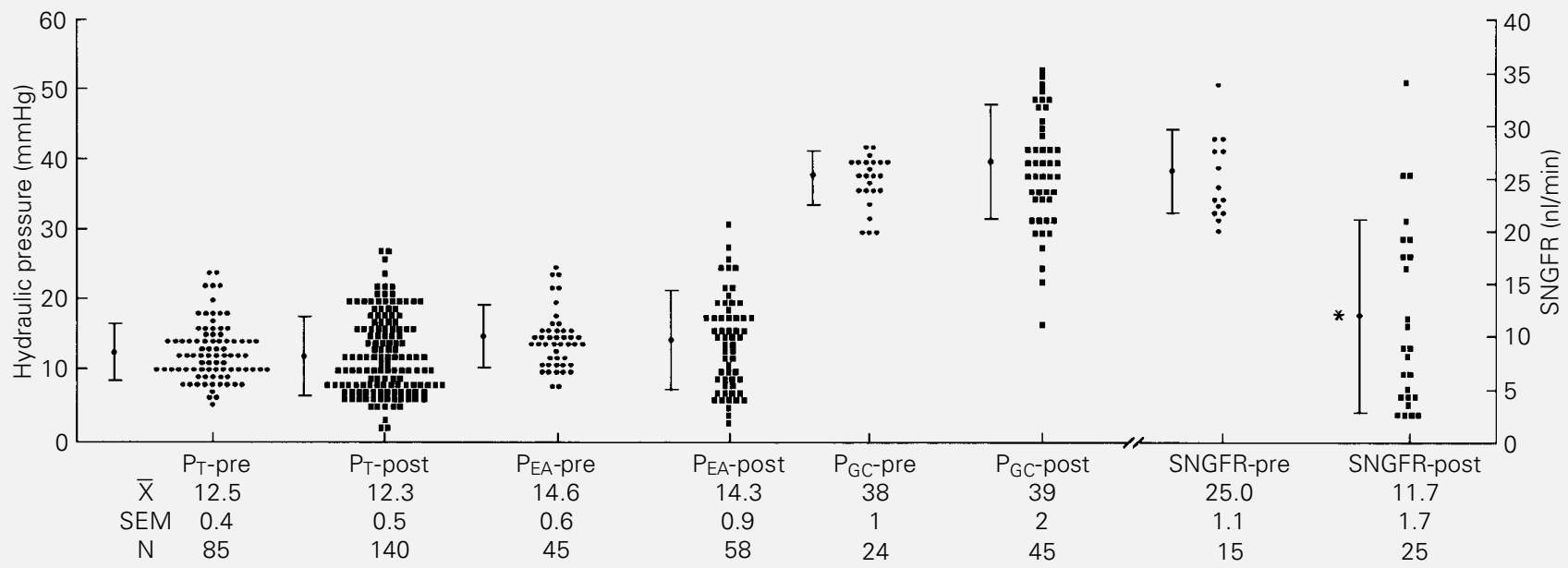

Figure 4 - Effect of epinephrine and norepinephrine on hydraulic pressures and single-nephron glomerular filtration rate (SNGFR). Hydraulic pressures $(\mathrm{mmHg})$ are indicated on the left ordinate for pre- and post-epinephrine (top panel) or norepinephrine (bottom panel), where $\mathrm{P}_{\mathrm{T}}=$ tubular hydraulic pressure, $P_{E A}=$ efferent arteriole hydraulic pressure, and $\mathrm{P}_{\mathrm{GC}}=$ intraglomerular hydraulic pressure. SNGFR data, reported as $\mathrm{nl} / \mathrm{min}$, are indicated on the right ordinate for pre- and post-epinephrine (top panel) or norepinephrine (bottom panel). Data are reported as means \pm SEM for $\mathrm{N}$ measurements and are presented below each column. ${ }^{*} \mathrm{P}<0.05$ vs pre (Student $t$-test). 
in the same animal. However, in spite of this variability, mean SNGFR was significantly reduced in both EPI- and NOR-treated groups. This result may be due to reductions in glomerular plasma flow rate and/or intraglomerular hydraulic pressure. Chen and Fleming (35) have demonstrated that the superficial afferent arterioles are more responsive to renal nerve stimulation and to microinfusion of norepinephrine and a reduction in $\mathrm{P}_{\mathrm{GC}}$ should be expected. However, in the present study we observed a heterogeneous response of glomerular arte- rioles to norepinephrine infusion, since mean $\mathrm{P}_{\mathrm{GC}}$ was not different from pre-administration levels, but an important scattering was also observed ranging from very low (18 $\mathrm{mmHg}$ ) to very high values $(57 \mathrm{mmHg}$. These results agree with the morphological findings, suggesting that these vasoactive drugs induce a heterogeneous distribution of blood flow in both superficial and juxtamedullary nephrons and do not shift the blood flow from the superficial to the medullary region.

\section{References}

1. Barajas L (1978). Innervation of the renal cortex. Federation Proceedings, 37: 11921201.

2. Valtin $H$ (1977). Structural and functional heterogeneity of mammalian nephrons. American Journal of Physiology, 233: F491-F501.

3. Dibona GF (1982). The functions of renal nerves. Review in Physiology, Biochemistry and Pharmacology, 94: 76-155.

4. Gottschalk CW, Moss NG \& Colindres R (1985). Neural control of renal function in health and disease. In: Seldin DW \& Giebisch G (Editors), The Kidney Physiology and Pathophysiology. Raven Press, New York.

5. Rokosh DG, Bailey A, Stewart AFR, Karns LR, Long CS \& Simpson PC (1994). Distribution of $\alpha 1 \mathrm{C}$-adrenergic receptor mRNA in adult rat tissues by RNase protection assay and comparison with $\alpha 1 \mathrm{~B}$ and $\alpha 1 \mathrm{D}$. Biochemical and Biophysical Research Communications, 200: 1177-1184.

6. Handy DE, Flordellis CS, Bogdanova NN, Bresnahan MR \& Gavras H (1993). Diverse tissue expression of rat $\alpha 2$ adrenergic receptor genes. Hypertension, 21: 861-865

7. Berkowitz DE, Price DT, Bello EA, Page SO \& Schwinn DA (1994). Localization of messenger RNA for three distinct $\alpha 2$-adrenergic receptor subtypes in human tissues. Anesthesiology, 81: 1235-1244.

8. Meinster B, Dagerlind A, Nicholas AP \& Hokfelt T (1994). Patterns of messenger RNA expression for adrenergic receptor subtypes in the rat kidney. Journal of Pharmacology and Experimental Therapeutics, 268: 1605-1611.
9. Arendshorst WJ \& Navar LG (1988). Renal circulation and glomerular hemodynamics. In: Schrier RW \& Gottschalk CW (Editors), Diseases of the Kidney. Little, Brown and Co., Boston, MA.

10. Gotshall RW \& Itskovitz HD (1977). Redistribution of renal cortical blood flow by renal nerve stimulation and norepinephrine infusion. Proceedings of the Society for Experimental Biology and Medicine, 154: 60-64.

11. Pomeranz $B H$, Birtch $A G$ \& Barger $A C$ (1968). Neural control of intrarenal blood flow. American Journal of Physiology, 215: 1067-1081.

12. Bentley MD, Lerman LO, Hoffman EA, Fiksen-Olsen MJ, Ritman EL \& Romero JC (1993). Measurement of renal perfusion and blood flow with fast computed tomography. Circulation Research, 74: 945-951.

13. Moore CD \& Gewertz BL (1982). Measurement of renal blood flow. Journal of Surgical Research, 32: 85-95.

14. Knox FG, Ritman EL \& Romero JC (1984). Intrarenal distribution of blood flow: evolution of a new approach to measurement. Kidney International, 25: 473-479.

15. McNay JL \& Abe Y (1970). Pressure-dependent heterogeneity of renal cortical blood flow in dogs. Circulation Research, 27: 571-587.

16. Opgenorth TJ, Fiksen-Olsen MJ \& Romero JC (1987). Role of prostaglandins in the cortical distribution of renal blood flow following reductions in renal perfusion pressure. Prostaglandins, 34: 591602.
17. Hanssen OE (1961). The relationship between glomerular filtration and length of the proximal convoluted tubules in mice. Acta Pathologica et Microbiologica Scandinavica, 53: 265-279.

18. Barros EJG, Boim MA, Ajzen $H$, Ramos OL \& Schor N (1987). Glomerular hemodynamics and hormonal participation in cyclosporine nephrotoxicity. Kidney International, 32: 19-25.

19. Lugon JR, Boim MA, Ramos OL, Ajzen $\mathrm{H}$ \& Schor N (1989). Renal function and glomerular hemodynamics in male endotoxemic rats. Kidney International, 36: 570575.

20. Vurek GG \& Pegran SE (1966). Fluorimetric method for the determination of nanogram quantities of inulin. Annals of Biochemistry, 16: 409-419.

21. Fuhr $J$, Kaczmarczyk $J$ \& Kruttgen $C D$ (1955). Eine einfache colorimetrische Methode zur Inulin Bestimmung für Nierenclear Untersuchungen bei Stoffwechselgesunden und Diabetikern. Klinische Wochenschrift, 33: 729-730.

22. Dworkin LD \& Brenner BM (1991). The renal circulations. In: Brenner BM \& Rector Jr FC (Editors), The Kidney. WB Saunders, Philadelphia.

23. Romero JC, Bentley MD, Vanhoutte PM \& Knox FG (1989). Intrarenal mechanisms that regulate sodium excretion in relationship to changes in blood pressure. Mayo Clinic Proceedings, 64: 1406-1424.

24. Kirchheim H, Ehmke H \& Person $P$ (1989). Sympathetic modulation of renal hemodynamics, renin release and sodium excretion. Klinische Wochenschrift, 67: 858864. 
25. Landsberg L \& Young J (1981). Sympathetic nervous system in hypertension. In: Brenner BM \& Stein JH (Editors), Hypertension. Churchill Livingstone, New York.

26. Blumenfeld JD (1993). Hypertension and adrenal disorders. Current Opinion in $\mathrm{Ne}$ phrology and Hypertension, 2: 274-282.

27. Muller R, Steffen HM, Weller P \& Krone $W$ (1994). Plasma catecholamines and adrenoreceptors in young hypertensive patients. Journal of Human Hypertension, 8: 351-355.

28. Galinier M, Senard JM, Valet $P$, Doazan JP, Durrieu G, Tran MA, Monstastruc JL \& Bounhoure JP (1994). Relationship between arterial blood pressure disturbances and alpha adrenoreceptor density. Clinical and Experimental Hypertension, 16: 373-389.
29. Uchino K, Frohlich ED, Nishikimi T, Isshiki T \& Kardon MB (1991). Spontaneously hypertensive rats demonstrate increased renal vascular alpha 1-adrenergic receptor responsiveness. American Journal of Physiology, 260: R889-R893.

30. Besarab A, Silva $P$, Landsberg $L$ \& Epstein $\mathrm{FH}$ (1977). Effect of catecholamines on tubular function in the isolated perfused rat kidney. American Journal of Physiology, 233: F39-F45.

31. Fink GD \& Brody MJ (1978). Continuous measurement of renal blood flow changes to renal nerve stimulation and intra-arterial drug administration in the rat. American Journal of Physiology, 234: $\mathrm{H} 219-\mathrm{H} 222$.

32. Trendelenburg AU, Limberger N \& Rump LC (1994). Alpha 2-adrenergic receptors of the $2 \mathrm{c}$ subtype mediate inhibition of norepinephrine release in human kidney cortex. Molecular Pharmacology, 45: 1168-1176.
33. Yamaguchi I (1993). Evidence for betaadrenoreceptors in rat proximal convoluted tubules. Kurume Medical Journal, 40: 159-167.

34. Minneman KP \& Esbenshade TA (1994). Alpha 1-adrenoreceptor subtypes. Annual Review of Pharmacology and Toxicology, 34P: 117-133

35. Chen J \& Fleming JT (1993). Juxtamedullary afferent and efferent arterioles constrict to renal nerve stimulation. Kidney International, 44: 684-691. 